\title{
CRYPTOSPORIDIUM: A SUMMER-AUTUMN EPIDEMIC?
}

$\mathrm{H}$ uman enteric infection with the protozoal parasite cryptosporidium was first reported in $1976^{1}$ and since that time many reports have been published of cryptosporidiosis affecting adults and children. In otherwise well individuals, this pathogen generally causes a mild, self-limiting gastroenteritis with watery, offensive diarrhoea which may be accompanied by vomiting, abdominal pain and fever. Prodromal respiratory symptoms may be noted, including cough and rhinorrhoea ${ }^{2}$. In the immunocompromised, such as patients with AIDS $^{3}$, cryptosporidium can cause severe, protracted and lifethreatening diarrhoea.

Cryptosporidium is usually transmitted directly from person to person via the faecal-oral route, and has been responsible for outbreaks of diarrhoea in child-care centres in this country and elsewhere ${ }^{2,4}$. The parasite also infects a variety of domestic animals, and human infection has been linked to calves and lambs with diarrhoea ${ }^{5}$. Rare pointsource outbreaks have been documented overseas, and have been traced to contamination of water supplies.

The Eastern Sydney Public Health Unit laboratory surveillance program receives reports from microbiology laboratories serving public hospitals in the Eastern Sydney Area and The Children's Hospital, Camperdown, and from several private pathology services, some of which have specimen collection centres in many parts of the State. A feature of this laboratory-based surveillance program is that many non-notifiable infections are reported.

In January 1991, the laboratory surveillance system detected a sudden and unexpected rise in the number of reported cryptosporidium isolates. In the first four weeks of 1991,21 cases were reported. The number of cases peaked at 85 during the third four-week period and returned to baseline levels in period six. This contrasted with the pattern during 1990 , when a maximum of 12 cases each four-week period had been reported. Figure 3 shows the number of cryptosporidium reports by four-week periods for 1990 and 1991.

The age and sex distributions of cases from the first 17 weeks of 1991 are shown in Figure 4. Of the 180 cases, 95 (53 per cent) were in females and 85 ( 47 per cent) in males. Most diagnoses were made in children: 78 per cent of cases were in children aged less than 15 years, and most of these (54 per cent) occurred in the 1-4 age group. The geographical distribution of cases by Health Area/Region shows that cases occurred throughout NSW and the ACT.

In a two-year survey of diarrhoeal illness reported from Fairfield Infectious Diseases Hospital, Melbourne, cryptosporidium was the second most frequently isolated parasite after giardia? In that study, 41 per cent of cases were among children under 15 years. Among white South African children and adults, cryptosporidium was the second most frequently identified pathogen after rotavirus, while 88 per cent of cases were in children under five years ${ }^{8}$.

There is no obvious explanation for the sudden peak in cases of cryptosporidiosis detected by the laboratory surveillance program. Participating laboratories did not change their routines for screening stool specimens for the parasite, and there was no sudden rise in community interest in the infection which might have influenced ordering patterns among general practitioners. Previous reports from the southern hemisphere have suggested a seasonal increase in incidence of cryptosporidiosis during the late summer months ${ }^{7 \cdot 9}$.

\section{FIGURE 3}

REPORTED CASES BY FOUR-WEEK PERIOD FOR 1990 AND 1991

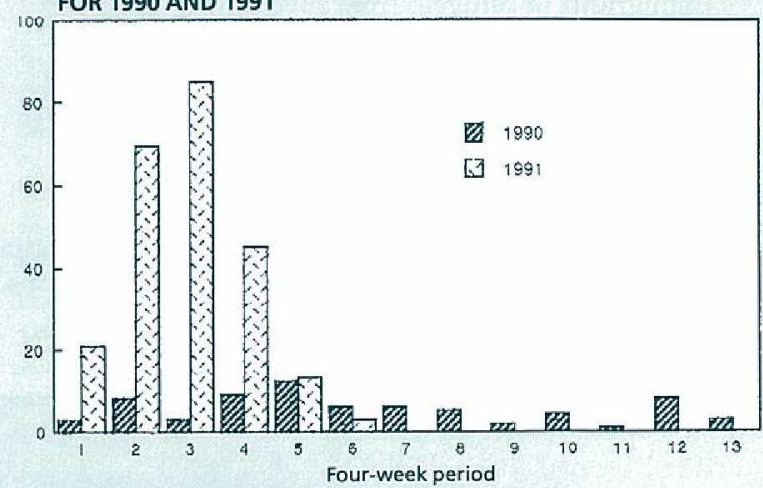

FIGURE 4

AGE-SEX DISTRIBUTION OF

180 CASES

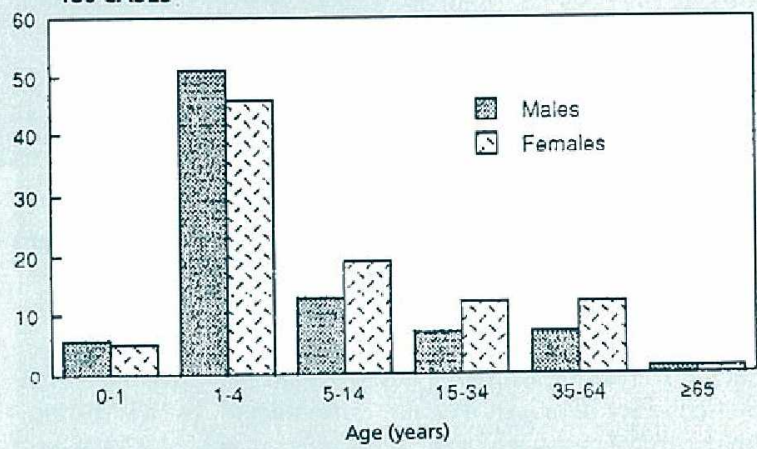

A similar phenomenon was uoserved in South Australia, as evidenced by a recent report from Adelaide Children's Hospital that cryptosporidial oocysts were identified in almost 30 per cent of children presenting with diarrhoea during January and February $1991^{10}$. This observation and the present report together suggest that a widespread epidemic of cryptosporidiosis occurred during the summerautumn months of 1991 .

Mark J Ferson, Specialist-in-charge Marie-Louise Stokes, Public Health Medical Officer Sydney $M$ Bell, Medical Officer of Health Public Health Unit, Eastern Sydney Area Health Service

1. Nime FA, Burek JD, Page DL, Holscher MA, Yardley JH. Acute enterocolitis in a human being infected with the protozoan cryptosporidium. Gastroenterology 1976; 70:592-598. 2. Cruikshank R, Ashdown L, Croese J. Human cryptosporidiosis in North Queensland. Aust NZ J Med 1988; 18:582-586.

3. Ravn P, Lundgren JD, Kjaeldgaard P, Holten-Anderson W, Hojlyng N, Nielsen JO, Gaub J. Nosocomial outbreak of cryptosporidiosis in AIDS patients. Br Med J 1991; 302:277-280.

4. Combee CL, Collinge ML, Britt EM. Cryptosporidiosis in a hospital. associated day care center. Pediatr Infect Dis 1986; 5:528-532. 5. O'Donoghue PJ. Cryptosporidium infections in man, animals, birds

and fish. Aust Vet $J$ 1985; 62:253-258. 6. Gallaher MM, Herndon J, Nims LJ, Sterling CR, Grabowski DJ,
HF. Cryptosporidiosis and surface water. Am J Public Health 1989; 79:39-42

7. Biggs B-A, Megna R, Wickremesinghe S, Dwyer B. Human infection with Cryptosporidium spp: results of a 24 -month survey. Med J Aust 1987; 147:175-177.

8. Steele AD, Gove E, Meewes PJ. Cryptosporidiosis in white patients in South Africa. I Infect 1989; 19:281-285.

9. Fripp PJ, Bothma MT, Crewe-Brown HH. Four years of

cryptosporidiosis at GaRankuwa Hospital. I Infect 1991; 23:93-100.

10. van Leeuwen P, Lawrence A, Hansman D. An outbreak of

10. van Leeuwen P, Lawrence Am children in Adelaide. Med J Aust 1991; 154:708-709 